\title{
Breastfeeding and infant growth outcomes in the context of intensive peer counselling support in two communities in Bangladesh
}

Rukhsana Haider ${ }^{1 *}$ and Kuntal Kumar Saha ${ }^{2}$

\begin{abstract}
Background: Exclusive breastfeeding and growth faltering during infancy remain challenges in Bangladesh. The Training \& Assistance for Health \& Nutrition Foundation has been working to address this gap through community-based peer counsellors since 2000. In this paper, we assessed the programme's progress, particularly with respect to early initiation of breastfeeding and exclusive breastfeeding for normal birth weight, as well as for low birth weight (LBW) infants.
\end{abstract}

Methods: The peer counselling programme is continuing in rural and urban areas of Bangladesh, but only data collected between January 2013 and June 2015 is presented in this descriptive study. Intensive breastfeeding counselling was provided to women during the third trimester of pregnancy and 6 months postpartum by well-trained peer counsellors. They recorded data on infants' birth weight, feeding practices and body weight every month and submitted these for computer entry. Weight measurements were converted to weight-for-age Z-scores (WAZ) and growth patterns assessed by comparing attained body weights with the World Health Organization (WHO) 2006 Child Growth Standards.

Results: A total of 994 infants were born during the study period; $94 \%$ were normal birth weight and $6 \%$ were LBW $(<2.5 \mathrm{~kg})$. Initiation of breastfeeding within one hour of birth was reported by $94 \%$ of counselled mothers in both groups. The prevalence of exclusive breastfeeding at 6 months was $94 \%$ in the normal birth weight infants and $92 \%$ in the LBW infants, and their mean body weights were $7.5 \pm 0.8 \mathrm{~kg}$ and $6.6 \pm 0.7 \mathrm{~kg}$ respectively. There was no growth faltering in these infants during 6 months. Underweight rates in normal birth weight infants remained similar (2.2\% at 1 month and $2.5 \%$ at 6 months), whereas underweight rates in LBW infants decreased from $42.1 \%$ at 1 month to $21.1 \%$ at 6 months.

Conclusions: In the context of a well-structured programme setting, and under the described circumstances, it seems likely that the well-trained and supervised community-based peer counsellors could assist in encouraging and helping mothers of both normal birth weight and LBW infants to initiate breastfeeding within one hour and to continue exclusive breastfeeding until 6 months of age. Our data suggest that they may also have contributed towards prevention of growth faltering in these infants.

Keywords: Community-based peer counsellors, Exclusive breastfeeding, Low birth weight, Normal birth weight, Growth, Bangladesh

\footnotetext{
* Correspondence: rukhsana.haider@gmail.com

${ }^{1}$ Training \& Assistance for Health \& Nutrition Foundation (TAHN), Banani,

Dhaka, Bangladesh

Full list of author information is available at the end of the article
} 


\section{Background}

Optimal breastfeeding under 2 years of age has the greatest impact on child survival with the potential to prevent $13 \%$ of all deaths in children under 5 years [1]. Systematic reviews have shown that exclusive breastfeeding for 6 months compared to exclusive breastfeeding for 3 to 4 months, can decrease diarrheal morbidity and prolong lactational amenorrhea while incurring no growth deficit among infants either in low or high income countries $[2,3]$. In addition to the short-term effects of breastfeeding on reduction of morbidity and mortality [4, 5] and improvement in cognitive and brain development [6, 7], recent evidence further highlights the long-term effects on intelligence, educational attainment and income [8-10].

Breastfeeding promotion was initiated in Bangladesh in 1989, focusing initially on meetings with health professionals. It was followed by implementation of the Baby-Friendly Hospital Initiative in maternity hospitals, and intensified after the World Health Organization's recommendation in 2002 to breastfeed infants exclusively for the first 6 months of life [11]. For several years however, the national prevalence of exclusive breastfeeding was stagnant, around $40 \%$, then rose suddenly to $64 \%$ in 2011 [12] but fell soon after to $55 \%$ in 2014 [13]. Although the under-five child malnutrition rates are decreasing slowly, they are still high with $36 \%$ stunted, $14 \%$ wasted and $33 \%$ underweight children in 2014 [13].

LBW rates on the other hand, continue to be high. While the only national survey that recorded birth weights in 2003-4 reported that $36 \%$ of infants were born LBW and $77 \%$ had intrauterine growth retardation [14], a report from the urban slums of Dhaka showed the LBW prevalence was $46 \%$ with $70 \%$ small for gestational age (SGA) and $17 \%$ preterm infants [15]. Recently, routine surveillance from a northern part of the country has documented even higher LBW rates of $55 \%$ with $22 \%$ preterm births [16].

Community-based breastfeeding peer counselling has been successful in increasing exclusive breastfeeding rates in Bangladesh [17] and elsewhere [18, 19]. Training \& Assistance for Health \& Nutrition Foundation (TAHN) was established in 2000 to enable the peer counsellors to continue working after our initial research [17] was completed, and to provide training on breastfeeding promotion and support to government and nongovernment organisations. Since the last few years however, the peer counsellors have been mentioning that although the LBW infants were given more attention, they still did not grow as well as the normal birth weight ones. A literature search showed a study from the Philippines [20] had selected term LBW infants in hospital and provided follow-up counselling and support to improve breastfeeding practices, but we found no reports that supported mothers of LBW babies at the community/household level. While acknowledging that effective breastfeeding promotion can improve breastfeeding patterns, the effects on growth are not always clear or conclusive [21-23]. Recognising that LBW infants can have unique breastfeeding problems and may have increased health risks [24], including delayed initiation that could increase neonatal mortality [25] and considering our own peer counsellors' observations about problems with LBW babies, we decided to assess if, after counselling, there were any differences regarding their breastfeeding outcomes. The primary objective of this descriptive study thus was to examine if peer counsellors were continuing to have an impact on early initiation and exclusive breastfeeding practices of infants in their coverage areas (both normal birth weight and LBW), and if these practices could also improve the infants' growth. The ongoing programme setting provided an excellent opportunity to do so.

\section{Methods \\ Setting}

The setting for this study was TAHN Foundation's programme areas in Badda, Dhaka city, and Anowara, a rural sub-district of Chittagong.

\section{Study design}

This was a descriptive study, with the aim of documenting process, outputs and outcomes related to community-based peer counselling and breastfeeding.

\section{Selection and training of peer counsellors}

The peer counsellors are married women who have breastfed their own babies for at least 1 year (not necessary to have exclusively breastfed), have minimum 8 years of formal schooling, have lived in the same community for several years and are motivated to help other women improve their infant and child feeding and caring practices. They were trained using adapted, simplified versions of the WHO/UNICEF breastfeeding counselling course [26] as has been described elsewhere [27] and the national infant and young child feeding (IYCF) training guidelines [28]. In brief, the "classroom" breastfeeding training was conducted for four hours per day over 4 days, using locally adapted training materials. Practical demonstrations were held for counselling and communication skills with emphasis on; position and attachment for breastfeeding, encouraging exclusive breastfeeding, expression of breastmilk and feeding babies breastmilk with a small cup, and for breastfeeding related problem solving. The trainees were then trained "handson" for 6 days in their communities, counselling pregnant women and mothers of infants $0-6$ months of age on 
early initiation and exclusive breastfeeding. After the peer counsellors had enrolled some mothers in the programme, the supervisors monitored at least $10 \%$ of the peer counsellors' counselling sessions using a pre-tested checklist and also took $10 \%$ of mothers' interviews for their feedback in the absence of the peer counsellors. During monthly meetings with peer counsellors, problems in the field were discussed. Refresher training was provided on quarterly basis for specific gaps in peer counselling, (e.g. position and attachment of LBW babies at mother's breast, demonstration of manual expression of breastmilk, identification and management of common problems etc.)

\section{Programme implementation}

Peer counsellors worked part time for the programme (3-4 $\mathrm{h}$ a day), and were paid an honorarium of Bangladeshi Taka 3,500-4,700 (approx. equivalent to USD 4560) per month, depending upon their experience in the programme. Each peer counsellor could provide services to about 50-60 pregnant and lactating mothers per month (with infants in different age groups who were followed up until 18 months). The catchment area for each peer counsellor was designated as households within 30 min walking distance from her residence. During 2012-2015, there were four peer counsellors in Badda and five in Anowara.

The peer counsellors enrolled pregnant women in the last trimester of pregnancy after receiving informed verbal consent and visited them at least two times during that period. Table 1 lists specific tasks that peer counsellors performed during home visits to pregnant women. During early infancy, peer counsellors visited mothers three times during the first month (within 2 days after delivery, between 7 and 10 days, and at 1 month) and thereafter on average, once a month until the infants

Table 1 Specific tasks of peer counsellors and key counselling topics during pregnancy

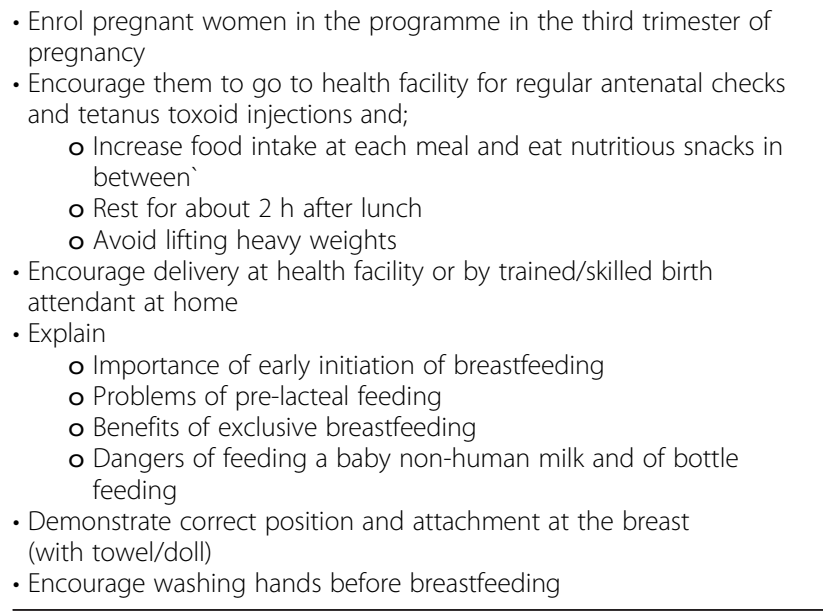

were 6 months old. If the mother or infant required more support, additional visits were also undertaken. The specific tasks that peer counsellors performed during postpartum home visits are shown in Table 2.

Influential family members, particularly grandmothers and fathers, were the secondary target group for the peer counsellors to promote optimal breastfeeding practices. Family members were requested to share the household chores so that mothers could give more time for caring and feeding the infant. The peer counsellors also motivated mothers to adopt appropriate hygiene practices and health seeking behaviour, such as for antenatal care, timely immunization of mother and child, and early treatment of any illness. Through the TAHN office, they provided mothers with Vitamin A supplements (200,000 IU units) soon after delivery, advised them to buy iron and folic acid tablets (they were provided only if she could not afford to buy) and to continue taking these until infants were 3 months old. Kangaroo care [24] was demonstrated to mothers with infants below $2000 \mathrm{~g}$ and they were encouraged to continue using this method until babies weighed $2500 \mathrm{~g}$. If there was a specific problem that the peer counsellor could not handle, she referred the mother either to a health facility (with a referral slip) or to the programme supervisors.

\section{Sample size and sampling}

Using an exclusive breastfeeding rate of $32 \%$ for $4-5$ month old infants, estimated from the national Bangladesh Demographic and Health Survey of 2014 [13], and expecting an increase of at least $48 \%$ in the peer counselled mothers (to reach $80 \%$ exclusive breastfeeding) with $80 \%$ power, we calculated a sample size of about 200 mothers. As we planned to study all the mothers who had been available in the programme during the period specified, and as we had more mothers than were needed for the analysis, we thought further calculations for a design effect were not necessary. But if we calculate for a design effect of 2, the total number would come to 400 mothers who had completed 6 months of follow-up.

Table 2 Specific tasks of peer counsellors and key counselling messages during first 6 months

\footnotetext{
- Remind mothers about

o Benefits of exclusive breastfeeding

o Dangers of non-human milk and of bottle feeding

- Washing hands before breastfeeding

- Observe position and attachment at the breast and correct if required

- Check if mother understands how she will know that baby is

getting sufficient breastmilk

- Emphasise correct usage of lactation amenorrhoea method (LAM) for contraception and other methods if and when indicated

- Demonstrate and check expression of breastmilk and feeding baby with small cup

- Praise and encourage to continue exclusive breastfeeding
} 
Since we wanted to investigate what impact peer counsellors were having on breastfeeding practices, all households with pregnant women in a peer counsellor's catchment area were included in the programme. A peer counsellor's area covered approximately 4,000 households in the urban slums in Badda, Dhaka city and 2,450 households in rural Anowara. From January 2013 to June 2015, a total of 1838 mothers were counselled, but only babies born during that period with recorded birth weight, and who had completed 6 months followup were included in this study. Mothers were excluded because of out-migration, if they had more than three living children, resided more than one hour away from the peer counsellor's house, refused peer counsellor's services, or if their infants had died. Also excluded were twins and infants with suspected congenital problems.

\section{Infant feeding practices}

Information about infant feeding practices was collected by the peer counsellors every month and recorded in their registers. Feeding practices were based on 24-h recall during a particular visit. Continued exclusive breastfeeding from birth to 6 months was recorded if at each consecutive visit and between visits, the mothers reported not having given anything but breastmilk to their babies. If water, honey, sugar-water etc. were fed in the first 3 days of life or later on, infants were labelled as predominantly breastfed [29], or if other milk or solids were given, as partially breastfed [30].

\section{Weight measurements}

Birth weights and monthly weights of infants were measured using electronic scales with $100 \mathrm{~g}$ precision (Tanita, Japan). Birth weights were recorded at home within 2 days of birth. A mother and her infant were first weighed together, and then the mother alone to obtain the infant's weight by subtraction. For each measurement, at least two readings were taken and the average weight noted. Standardisation of the weighing scales was performed whenever the supervisors went for field visits.

\section{In-depth interviews}

Staff conducted in-depth interviews (over phone or in person) with mothers of infants who had been partially breastfed at any time during 6 months with the intention of identifying the main reasons and difficulties that had may have led to discontinuation of exclusive breastfeeding.

\section{Data analysis}

Data about timing of initiation of breastfeeding and breastfeeding status on 24-h recall at each monthly visit were analysed. Timing of initiation of breastfeeding was estimated as the length of time in minutes and hours between delivery and the actual time when breastfeeding had started. Prevalence of exclusive breastfeeding among infants was ascertained from the reports as described earlier.

Weight measurements were converted to weight-forage Z-scores (WAZ) according to the WHO 2006 Child Growth Standards [31]. Underweight was defined as $<-2$ Z-score of WAZ. Growth patterns of boys and girls (normal birth weight and LBW) were examined by comparing their attained monthly weights with the WHO 2006 Child Growth Standards.

Data were analysed using SPSS Version 17 (SPSS Inc., Chicago, USA). Descriptive analyses included frequencies and contingency tables, means and standard deviations. Statistical tests were not used to compare LBW with normal birth weight infants and mothers since the numbers in the former group were comparatively very small.

\section{Results}

\section{General characteristics of the sample}

A total of 1104 babies were born over the 2 and a half years between January 2013 and June 2015, among whom birth weights were recorded for 994 (Fig. 1). About $6 \%$ of the babies were LBW $(<2.5 \mathrm{~kg})$. Only $1.6 \%$ of mothers had refused peer counsellor's services, either because they/family preferred to get nutrition/ infant feeding advice from a doctor, or they did not want any outsider to visit their homes.

Mean birth weight of the normal birth weight infants was $3.1 \pm 0.3 \mathrm{~kg}$ and that of the LBW infants was $2.1 \pm$ $0.2 \mathrm{~kg}$. There were no differences in the mean age, number of previous children, place of delivery, and health personnel who conducted the delivery among mothers of the normal birth weight and LBW infants (Table 3). Only the percentage of mothers of LBW infants who had no education was higher (13\%) compared to mothers of normal birth weight infants (5\%), but their numbers were small. About half of the mothers of normal birth weight infants delivered at health facilities (53\%), compared to the mothers of LBW infants (60\%). Similarly, a higher proportion of mothers of LBW infants delivered before 37 weeks of gestation, with more Caesarean sections (26\%) than mothers of normal birth weight infants (21\%).

\section{Breastfeeding practices}

Reported breastfeeding initiation within one hour of birth was high for all the infants, about $94 \%$ in both the normal birth weight and LBW infants (Table 4). Initiation was delayed when the infants were delivered by Caesarean section, and/or infants were separated from their mothers in the health facility, or were perceived to be too weak to suckle at the breast. Exclusive breastfeeding rates at 6 months using 24-h recall (94\% for normal birth weight and $92 \%$ for LBW infants) were similar to 


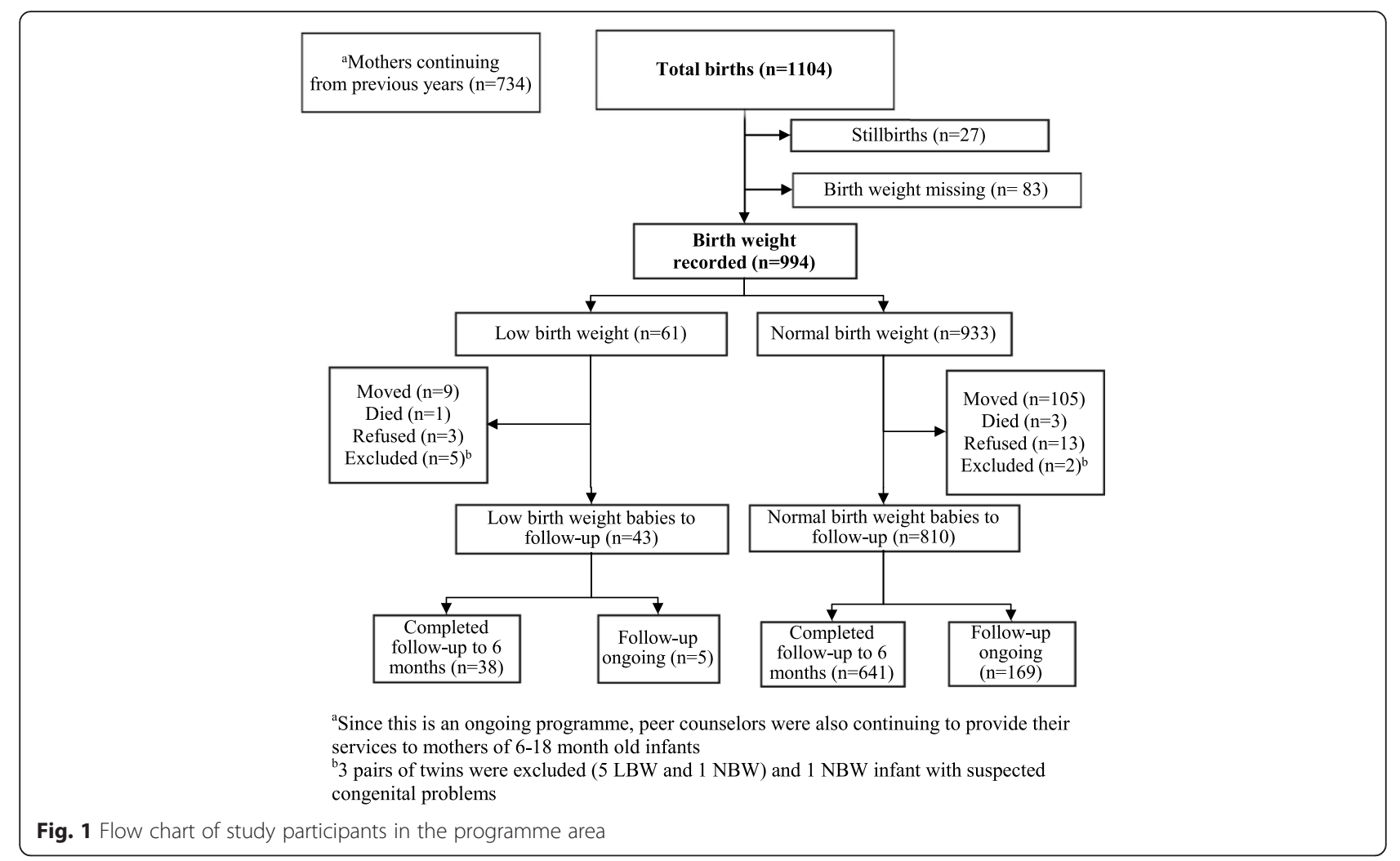

those obtained by using post-delivery and consecutive monthly feeding practices data for 6 months $(91 \%$ for normal birth weight and $92 \%$ for LBW infants).

Fifty-three mothers of the normal birth weight infants had fed their infants other milk at some time during the 6 months, but none of the mothers of the LBW infants had fed anything else. The previous group of mothers were asked (through staff visits/phone calls) the reasons for this supplementation (data provided in Table 5). Apart from a small number of infants who were separated from their mothers in the first 3 days, and mothers being very unwell during the first month $(27 \%)$, the commonest answer was that the grandparents wanted to feed the baby other milk (17 \%). In $30 \%$ cases, doctors had advised to add other milk, whereas mothers themselves took the decision to do so in $43 \%$ of cases, and other family members in $6 \%$ of cases.

\section{Growth patterns and underweight prevalence in normal birth weight and LBW infants}

At 6 months, the mean body weight of normal birth weight boys was $7.8 \pm 0.8 \mathrm{~kg}$, compared to $6.8 \pm 0.8 \mathrm{~kg}$ for the LBW boys. Likewise, at 6 months, the mean body weights were $7.2 \pm 0.8 \mathrm{~kg}$ for normal birth weight girls and $6.5 \pm 0.6 \mathrm{~kg}$ for the LBW girls. Initially the normal birth weight and LBW boys and girls grew parallel to, but in a lower track than the infants in the WHO growth standards (Figs. 2 and 3), but by 5 months the gap between the normal birth weight girls and those in the WHO standards had almost disappeared.

The underweight (WAZ $<-2 \quad \mathrm{Z}$-score) rates for the normal birth weight infants remained between $2.0 \%$ and $3.1 \%$ during the first 6 months of life, with $97 \%$ above -2 Z-score. In contrast, the underweight rates for the LBW infants decreased from $42 \%$ at 1 month to $22 \%$ at 6 months of age, so $77 \%$ were above -2 Z-score (Fig. 4).

\section{Discussion}

This study was carried out to document the progress of a small-scale programme that has been promoting optimal breastfeeding practices through peer counsellors in urban and rural settings in Bangladesh for several years. High rates of early initiation of breastfeeding and of exclusive breastfeeding were seen in the programme area. At the same time, there were no signs of growth faltering in the infants of the counselled mothers during the first 6 months.

As peer counsellors were requested to give more emphasis on explaining the importance of initiating breastfeeding within the first hour of birth, the current reported initiation rate is higher at $94 \%$ versus $79 \%$ in 2011 [32] and substantially higher than the $57 \%$ initiation rates reported in the Multiple Indicator Cluster Survey of 2013-14 [33]. Our latest rate of $94 \%$ exclusive breastfeeding prevalence at six months was however consistent with our earlier findings of $88 \%$ [32] and comparatively much higher than that reported in the 
Table 3 General characteristics of mothers and infants in the programme

\begin{tabular}{|c|c|c|}
\hline & Normal birth weight & Low birth weight \\
\hline & $n=641$ & $n=38$ \\
\hline & Mean \pm SD (Range) & Mean \pm SD (Range) \\
\hline Infant Birth weight (Kg) & $3.1 \pm 0.34(2.5-4.4)$ & $2.1 \pm 0.23(1.5-2.4)$ \\
\hline Mothers age (years) & $22.2 \pm 3.3(16-35)$ & $23.1 \pm 4.0(18-33)$ \\
\hline Mothers education & & \\
\hline Years of schooling & $7.1 \pm 3.1$ & $6.5 \pm 3.5$ \\
\hline & $\%$ & $\%$ \\
\hline No education & 5.3 & 13.2 \\
\hline With education & 94.7 & 86.8 \\
\hline Previous children & & \\
\hline 0 & 59.1 & 50.0 \\
\hline$\geq 1$ & 40.9 & 50.0 \\
\hline Previous child was EBF & & \\
\hline Yes & 95.8 & 68.4 \\
\hline No & 4.2 & 31.6 \\
\hline Gestational age (weeks) & & \\
\hline$<37$ & 3.0 & 13.2 \\
\hline$>37$ & 97.0 & 86.8 \\
\hline Place of delivery & & \\
\hline Health facility & 53.5 & 60.5 \\
\hline Home & 46.5 & 39.5 \\
\hline Delivery type & & \\
\hline Normal vaginal & 78.5 & 73.7 \\
\hline Caesarean section & 21.5 & 26.3 \\
\hline Delivered by & & \\
\hline Doctor/Nurse & 52.3 & 63.2 \\
\hline TBA & 47.7 & 36.8 \\
\hline
\end{tabular}

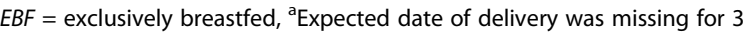
normal birth weight infants, $T B A=$ traditional birth attendant

2014 national survey (55 \% exclusive breastfeeding among 0-6 month infants) [13]. These results thus seem to suggest that the peer counselling intervention may be making a difference in the breastfeeding rates in these areas. This is a likely possibility as our results are also similar to those obtained from a cluster-randomized evaluation of a large nongovernment project in Bangladesh, where the exclusive breastfeeding rate in the intervention areas during 5 years rose to $86 \%$ compared to $51 \%$ in comparison areas [34]. It is of interest to note, however, that the intervention package in the latter project had huge resources and included a combination of group and inter-personal counselling by staff and outreach workers/paid volunteers, mass media communications, community mobilization and advocacy to create an enabling environment for optimal IYCF practices.

Also noteworthy is that our facility-based delivery rates at $60 \%$ were higher than the $40 \%$ national rates
Table 4 Initiation of breastfeeding and prevalence of exclusive breastfeeding in normal and low birth weight infants

\begin{tabular}{lll}
\hline & $\begin{array}{l}\text { Normal birth weight } \\
n=641 \\
(\%)\end{array}$ & $\begin{array}{l}\text { Low birth weight } \\
n=38 \\
(\%)\end{array}$ \\
\hline $\begin{array}{ll}\text { Initiation of breastfeeding } \\
\text { Within } 1 \text { h of birth }\end{array}$ & 93.9 & 94.7 \\
Within 3 days or more & 6.1 & 5.3 \\
Feeding Status at 6 months & & \\
EBF $^{\text {a }}$ & 93.8 & 92.1 \\
Predominant breastfeeding & 0.2 & 2.6 \\
Partial breastfeeding & 5.9 & 5.3 \\
No breastfeeding & 0.2 & 0.0 \\
Feeding Status, birth to & & \\
6 months & & \\
EBF & \\
Predominant breastfeeding & 0.3 & 92.1 \\
Partial breastfeeding & 8.3 & 2.6 \\
No breastfeeding & 0.2 & 5.3 \\
\hline a Using 24-h recall at infants' completion of 6 months visit \\
b Using 24-h recall within 3 days and at every monthly visit from 1 to 6 months
\end{tabular}

[13]. This may have happened because peer counsellors encouraged mothers to go to health facilities for delivery, explained the risks of home delivery by untrained birth attendants, and gave referral slips when required for health facilities where TAHN had already established linkages and staff were supportive of breastfeeding.

Understandably, some of the mothers did have difficulties in continuing exclusive breastfeeding, and their reasons are mentioned in Table 5. In other cases, though, it was the doctors or the grandparents who advised other milk or other liquids or foods to be given in addition to breastmilk. Some of the quoted reasons were similar to those that have been reported in one of our earlier reports [35] and other studies elsewhere $[36,37]$ which indicate that more efforts will be required to identify and target vulnerable mothers and to provide them (and their families) with additional information and support so that they feel more confident in their ability to breastfeed exclusively.

As our peer counsellors had expressed concerns regarding difficulties in breastfeeding by mothers of the LBW infants, we tried to find reports of breastfeeding/ breastfeeding counselling of LBW infants and found only three reports, all from the Philippines [20, 38, 39]. While the earlier study had reported that LBW infants were breastfed less compared to infants with normal birth weight [38], the later one showed that peer counselling of mothers of term LBW infants after hospital discharge could achieve $44 \%$ exclusive breastfeeding at 6 months compared to $7 \%$ in mothers who received only childcare counselling, and none in the controls [20]. The same 
Table 5 Reasons and decision makers for adding other milk along with breastmilk in normal birth weight infants

\begin{tabular}{llll}
\hline & Reasons for adding other milk & Who decided/ started & No. and (\%) of mothers \\
\hline 1 & Added within $1^{\text {st }} 3$ days after C/Sec ${ }^{\text {, } \text { as mother separated from baby }}$ & Doctor & $3(6)$ \\
2 & Added within $1^{\text {st }} 3$ days of normal delivery, as mother was very sick & Family members & $8(15)$ \\
3 & C/Sec ${ }^{\text {a }}$ followed by pain in abdomen and body for many days. Mother & Doctor & $5(9)$ \\
4 & unable to care for baby properly, who cried a lot & Doctor & $2(4)$ \\
5 & Baby sick (cough, fever, breathing problem, diarrhoea) & Pharmacy salesman & $9(17)$ \\
6 & Baby cried at night & Grandparents & $7(13)$ \\
7 & Wanted to feed baby other milk along with breastmilk & Mother & $7(13)$ \\
8 & Mother thought she had insufficient milk & Mother & $3(6)$ \\
9 & Mother and others thought baby did not want breastmilk & Mother & $4(7)$ \\
10 & Mother was sick (chicken pox, high fever) & Mother & $2(4)$ \\
TOTAL & Mother went out for work (factory, housemaid) & Mother & $53(100)$ \\
\hline
\end{tabular}

${ }^{\mathrm{a}} \mathrm{C} / \mathrm{Sec}$ : Caesarean section

authors also showed that those infants who were exclusively breastfed from birth to 6 months had very little diarrhoea compared to partially breastfed and nonbreastfed infants and showed catch-up growth in the first 4 months [39]. So although the LBW group in our study was small, it is quite remarkable all the mothers managed to breastfeed their infants exclusively for 6 months.

When it comes to peer counselling, a comprehensive review of published research has shown that peer counsellors are effective in improving rates of breastfeeding initiation, duration and exclusivity while significantly decreasing the incidence of diarrhoea in infants and increasing lactation amenorrhoea [19]. The review's authors further emphasize that "although interventions have focused primarily on models serving low-income women, this should not be interpreted as implying that only the low-income group benefits from peer counselling. Where healthcare resources are limited, the peer counsellors may be the only feasible means to provide breastfeeding education and support to prevent early childhood illness and growth faltering" [19]. And yet, peer counselling is an option, which unfortunately, has not been utilised widely in Bangladesh or in the South Asian region.

Looking at the growth studies, we have an earlier report from a rural area that showed Bangladeshi infants were shorter, lighter and thinner when compared with the WHO growth standards [40]. Our findings are consistent with these findings as growth and weight of both normal birth weight and LBW infants remained parallel to, but somewhat below the WHO child growth standards. At the same time, except for slower growth in the first month, no signs of growth faltering were seen in either group of infants. On the contrary, by 5 months of age the gap between the normal birth weight girls and

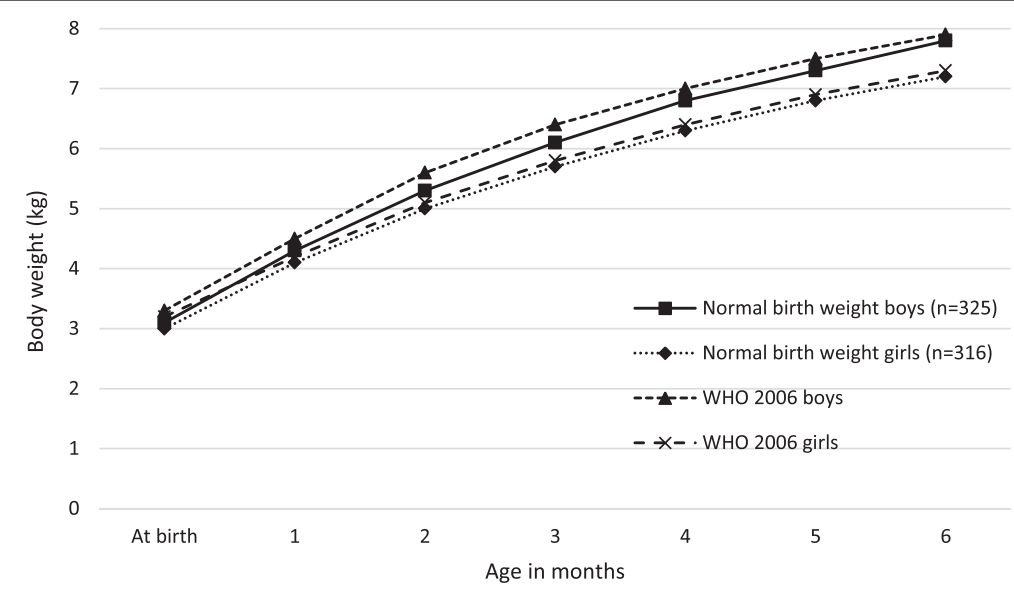

Fig. 2 Comparison of body weight of normal birth weight infants with WHO child growth standards 


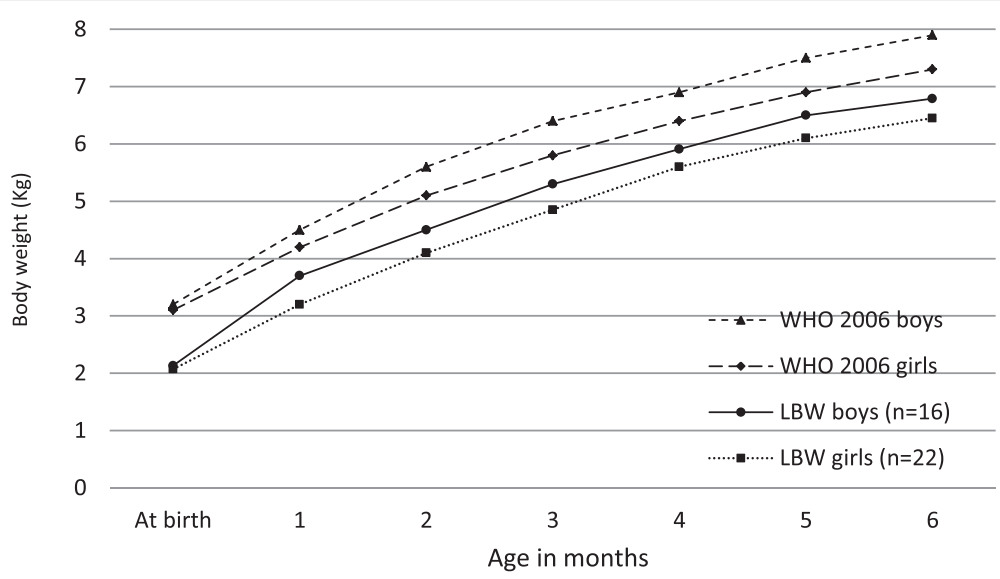

Fig. 3 Comparison of body weight of low birth weight infants with WHO child growth standards

those in the WHO standards had almost disappeared. On the whole, and especially since child undernutrition rates are so high in the country, these growth patterns are encouraging and suggest that peer counsellors' supportive services may also be contributing towards prevention of growth faltering in both normal birth weight and LBW infants. Larger studies, however, will be required to confirm these findings. An additional contributory factor may be the lower incidence of illness in these infants (as per peer counsellor's verbal reports), but that too, may be associated with better caring practices. It would be important to follow-up these children to monitor their complementary feeding patterns and examine its impact on their growth during early childhood.

We recognise several limitations of this assessment. We could not study a control group during the same period due to resource constraints. The number of LBW infants was much smaller than we had expected compared to the normal birth weight infants so we could not use any statistical tests for comparisons. We could not observe feeding practices at home and therefore relied on mother's recall of infant feeding. However, as both 24-h recall on current visit and feeding practices during the last two visits were collected every month, we assumed this provided reliable information on infant feeding, and comparison between the two methods reduced recall bias which as others have pointed out, is minimal [41-43]. Due to scarce resources and logistic setbacks, it was not possible to measure infants' lengths. We were thus unable to use length-for-age, length increments and stunting as indicators of nutritional status. Mothers' weights and heights were not recorded during pregnancy so the impact of their nutritional status, particularly weight gain during pregnancy, which is an important determinant of birth weights, could not be assessed. Our analyses did not take into account any confounders (such as a mothers' nutritional status) that may have influenced the outcomes, and that is probably

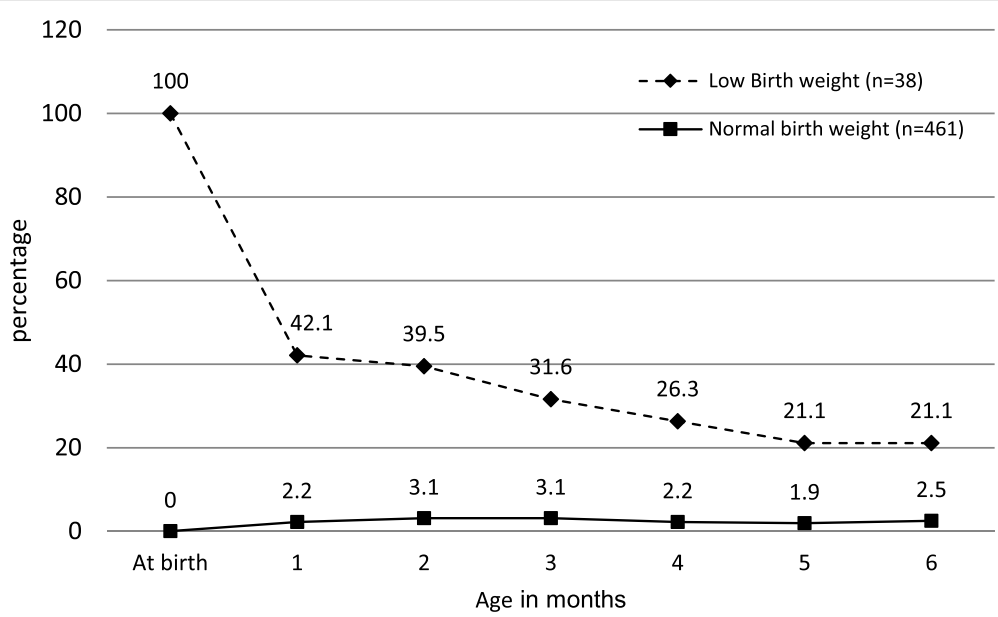

Fig. 4 Prevalence of underweight (WAZ <-2SD) among normal birth weight and low birth weight infants 
another limitation of this study. Finally, due to absence of birth weights of those who had delivered away from the programme area (particularly in other villages), it is difficult to extrapolate the results, and further investigation in larger programme settings would be needed.

The main strength of this study, however, is that it comes from programme areas where we have been working for 15 years, and each cohort of mothers and babies is followed up for 18 months. There is regular interaction, and good rapport between peer counsellors, mothers and their families and programme staff, so mothers share their views freely. Furthermore, we have presented information on all LBW infants, whether delivered vaginally or surgically, preterm or term, of primiparous or multiparous mothers. The analysis thus was truly representative of an actual programme setting and could act as a model to show that small-scale programmes can also achieve good results, and therefore coverage area should not be a deterrent for undertaking them. Of course there could be other competing explanations for all the positive findings, such as the presence of the programme in these areas for so many years. Thus there may well have been a change in the community's views towards exclusive breastfeeding, or more mothers may have grown up watching infants being exclusively breastfed, and being expected to do so themselves. It may also be argued that women who accept peer counselling could be different from those who do not, but we did not have many refusals in order to compare their characteristics. At the same time, it needs to be pointed out that the peer counsellors are basically extremely committed women. Their commitment has increased over time as they see the infants and young children of counselled mothers stay healthy and thrive, and their services are valued and respected by the community. It is not easy to find and keep such committed women, as often in rural communities women are not allowed to go from house to house, and be seen or talk to other men. The programme staff ensures that everything is explained clearly to the husbands and other significant family members when recruiting the peer counsellors, and also thank them for their support whenever they meet them.

Because of the dense population and low ratio of health staff to patients, it is well recognised that despite preventive health education being urgently needed, in actual practice time given for this is very limited [44]. This is more so where there are insufficient well child visits and domiciliary preventive health services. Frequent and targeted visits by community-based peer counsellors can be suggested, not only to encourage and support mothers to breastfeed exclusively, but also to promote and monitor infant growth, and to take timely action for improving their nutritional status.

\section{Conclusions}

In the context of a well-structured programme setting, and under the described circumstances, it seems likely that appropriately trained and supervised communitybased peer counsellors could assist in encouraging and helping mothers of both normal birth weight and LBW infants to initiate breastfeeding within 1 hour and to continue exclusive breastfeeding until 6 months of age. Our data suggest that they may also have contributed towards prevention of growth faltering of the infants.

\section{Abbreviations}

WHO, World Health Organization; LBW, low birth weight; WAZ, weight-forage Z score; SD, standard deviation; TAHN, training \& assistance for health \& nutrition foundation

\section{Acknowledgments \\ We are grateful to TAHN's Executive Board members and friends for financially supporting the programme. We are especially grateful to all the mothers and their families for giving time for counselling and for their cooperation with the Foundations' programme. The peer counsellors' excellent and dedicated services are appreciated. Thanks also to the Foundation's programme and field staff managers Rezaul Karim and Ratna Gomes, and local supervisor Progoti Singha, for supervising the peer counsellors and monitoring the programme, and to Md. Shariful Islam for data management and preliminary analysis. We are truly thankful to Dr Virginia Thorley and Dr Felicity Savage King for their valuable and helpful comments on an earlier version of this manuscript.}

\section{Authors' contributions}

$\mathrm{RH}$ participated in the conceptualization and design of the study, performed data collection and led the data analysis and preparation of the manuscript. KKS participated in the conceptualization and design of the study, and participated in the data analysis, interpretation of data and preparation of the manuscript. Both authors read and approved the final manuscript.

\section{Authors' information}

Rukhsana Haider is Founder and Chair of the Training \& Assistance for Health \& Nutrition Foundation (TAHN), Dhaka, Bangladesh.

Kuntal Kumar Saha is a Technical Officer at the Department of Nutrition for Health and Development, World Health Organization, Geneva, Switzerland.

\section{Competing interests}

The authors declare that they have no competing interests.

Ethics approval and consent to participate

Ethics approval was obtained from the Bangladesh Medical Research Council for on-going assessment of the programme. Informed verbal consent to participate in the programme was obtained from the pregnant mother and her influential family members on enrollment.

\section{Disclaimer}

KKS is a member of the World Health Organization. The author alone is responsible for the views expressed in this publication and they do not necessarily represent the decisions, policy or views of the World Health Organization.

\section{Author details}

${ }^{1}$ Training \& Assistance for Health \& Nutrition Foundation (TAHN), Banani, Dhaka, Bangladesh. 'Department of Nutrition for Health and Development, World Health Organization, Geneva, Switzerland.

Received: 12 December 2015 Accepted: 27 June 2016

Published online: 07 July 2016 


\section{References}

1. Black RE, Victora CG, Walker SP, Bhutta Z, Christian P, de Onis M, et al. Maternal and child undernutrition and overweight in low-income and middle-income countries. Lancet. 2013;382:427-51.

2. Kramer MS, Kakuma R. The optimal duration of exclusive breastfeeding. Adv Exp Med Biol. 2004:554:63-7.

3. Jolly K, Ingram L, Khan KS, Deeks JJ, Freemantle N, MacArthur C. Systematic review of peer support for breastfeeding continuation: meta regression analysis of the effect of setting, intensity and timing. BMJ. 2012;344:d8287.

4. WHO Collaborative Study Team on the Role of Breastfeeding on the Prevention of Infant Mortality. Effect of breastfeeding on infant and child mortality due to infectious diseases in less developed countries: a pooled analysis. Lancet. 2000;355:451-5.

5. Sankar MJ, Sinha B, Chowdhury R, Bhandari N, Taneja S, Martines J, Bahl R. Optimal breastfeeding practices and infant and child mortality: a systematic review and meta-analysis. Acta Paediatr. 2015;104:3-13.

6. Rao MR, Heidiger ML, Levine RJ, Naficy AB, Vik T. Effect of breastfeeding on cognitive development of infants born small for gestational age. Acta Paediatr. 2002;91:267-74.

7. Michaelsen KF, Lauritzen L, Jorgensen MH, Mortensen EL. Breast-feeding and brain development. Scand J Nutr. 2003;47:147-51.

8. Horta BL, Victora CG. Long-term effects of breastfeeding: A systematic review. Geneva: World Health Organization; 2013.

9. Horta BL, de Mola CL, Victora CG. Breastfeeding and intelligence: a systematic review and meta-analysis. Acta Paediatr. 2015;104:14-9.

10. Victora CG, Horta BL, Loret De Mola C, Quevedo L, Pinheiro RT, Gigante DP, Gonçalves H, Barros FC. Association between breastfeeding and intelligence, educational attainment, and income at 30 years of age: a prospective birth cohort study from Brazil. Lancet Glob Health. 2015;3:e199-205.

11. World Health Organization. Global Strategy for infant and young child feeding. Geneva: WHO/UNICEF; 2002.

12. National Institute of Population Research and Training (NIPORT), Ministry of Health and Family Welfare, Bangladesh, Mitra and Associates and the DHS Program, ICF International. Bangladesh Demographic and Health Survey, 2011. Dhaka, Bangladesh and Calverton, USA: NIPORT, Mitra and Associates and ICF International; 2013.

13. National Institute of Population Research and Training (NIPORT), Ministry of Health and Family Welfare, Bangladesh, Mitra and Associates and the DHS Program, ICF International. Bangladesh Demographic and Health Survey, Key Indicators, 2014. Dhaka, Bangladesh and Calverton, USA: NIPORT, Mitra and Associates and ICF International; 2015.

14. Bangladesh Bureau of Statistics and UNICEF. National low birth weight survey of Bangladesh 2003-2004. UNICEF Bangladesh. Dhaka, 2005. http:// www.unicef.org/bangladesh/Low_Birth_Weight_report.pdf.

15. Arifeen SE, Black RE, Caulfield LE, Antelman G, Baqui AH, Nahar Q, Alamgir S, Mahmud $\mathrm{H}$. Infant growth patterns in the slums of Dhaka in relation to birth weight, intrauterine growth retardation, and prematurity. Am J Clin Nutr. 2000;2000(72):1010-7.

16. Klemm RDW, Merrill RD, Wu L, Shamim AA, Ali H, Labrique A, et al. Low birthweight rates higher among Bangladeshi neonates measured during active birth surveillance compared to national survey data. Matern Child Nutr. 2015;11:583-94.

17. Haider R, Ashworth A, Kabir I, Huttly SRA. Effect of community-based peer counselors on exclusive breastfeeding practices in Dhaka, Bangladesh: a randomized controlled trial. Lancet. 2000;356:1643-7.

18. Morrow AL, Guerrero ML, Shults J, Calva JJ, Lutter C, Bravo J, et al. Efficacy of home-based counseling to promote exclusive breastfeeding: a randomized controlled trial. Lancet. 1999;353:1226-31.

19. Chapman DJ, Morel K, Anderson AK, Damio G, Perez-Escamilla R. Breastfeeding peer counseling: from efficacy through scale-up. J Hum Lact. 2010;26:314-26.

20. Agrasada GV, Gustafsson J, Kylberg E, Ewald U. Postnatal peer counseling on exclusive breastfeeding of low-birth weight infants: A randomized controlled trial. Acta Paediatr. 2005;94:1109-15.

21. Britton C, McCormick FM, Renfrew MJ, Wade A, King SE. Support for breastfeeding mothers. Cochrane Database Syst Rev. 2007;1:CD001141.

22. Renfrew MJ, McCormick FM, Wade A, Quinn B, Dowswell T. Support for healthy breastfeeding mothers with healthy term babies. Cochrane Database Syst Rev. 2012;5:CD001141.

23. Engebretsen IMS, Jackson D, Fadnes LT, Nankabirwa $V$, Diallo AH, Dohert $T$, Lombard C, et al. Growth effects of exclusive breastfeeding promotion by peer counsellors in sub-Saharan Africa: the cluster randomised PROMISE EBF trial. BMC Public Health. 2014;14:633.
24. Conde-Agudelo A, Belizán JM, Diaz-Rossello JL. Kangaroo mother care to reduce morbidity and mortality in low birthweight infants. Cochrane Database Syst Rev. 2011;3:CD002771.

25. Edmond KM, Zandoh C, Quigley MA, Emenga-Etego S, Owusu-Agyei S, Kirkwood B. Delayed breastfeeding initiation increases risk of neonatal mortality. Pediatrics. 2006;117:e380-6.

26. World Health Organization. Breastfeeding counselling: a training course. http://www.who.int/maternal_child_adolescent/documents/who_cdr_93_3/en/.

27. Haider R, Kabir I, Huttly SRA, Ashworth A. Training peer counselors to promote and support exclusive breastfeeding in Bangladesh. J Hum Lact. 2002;18:7-12.

28. National Nutrition Services. National Training Manual on IYCF, 2011. http:// aliveandthrive.org/wp-content/uploads/2014/11/Bangladesh-NationalTraining-Manual-on-IYCF-English.pdf.

29. World Bank. Family and community approaches to improve infant and young child nutrition in South Asia: a report of the World Bank South Asia region development marketplace. Washington DC, USA: World Bank; 2012.

30. WHO and UNICEF. Indicators for assessing infant and young child feeding practices. Part 1. Definitions. Conclusions of a consensus meeting held 6-8 November 2007 in Washington, USA. Washington, USA: WHO and UNICEF; 2008.

31. Labbok M, Krasovec K. Toward consistency in breastfeeding definitions. Stud Fam Plann. 1990;21:226-30.

32. World Health Organization, Multicentre Growth Reference Study Group. WHO Child Growth Standards: methods and development: length/heightfor-age, weight-for-age, weight-for-length, weight-for-height and body mass index-for-age. Geneva: WHO; 2006.

33. Bangladesh Bureau of Statistics and UNICEF. Progotir Pathey Multiple Indicator Cluster Survey 2012-2013, Key Findings. Govt. of the People's Republic of Bangladesh, Bangladesh Bureau of Statistics and UNICEF Bangladesh 2014, Dhaka, Bangladesh.

34. Saha KK, Khaled A, Chowdhury AH, Kennedy A, Tyagi P, Nguyen PH et al. Alive \& Thrive Bangladesh: Impact Evaluation 2014 Final Report. Dhaka; 2015

35. Haider R, Islam A, Hamadani J, Amin NJ, Kabir I, Malek MA, Mahalanabis D Habte D. Breastfeeding counselling in a diarrhoeal disease hospital. Bull WHO. 1996;74:173-9

36. Nankunda J, Tumwine JK, Soltvedt A, Semiyaga N, Ndeezi G, Tylleskar T. Community-based peer counsellors for support of exclusive breastfeeding; experiences from rural Uganda. Int Breastfeed J. 2006:1:19.

37. Yeneabat T, Belachew T, Haile M. Determinants of cessation of exclusive breastfeeding in Ankesha Guagusa Woreda Awi Zone, Northwest Ethiopia; a cross-sectional study. BMC Pregnancy Childbirth. 2014;14:262. http://www. biomedcentral.com/content/pdf/1471-2393-14-262.pdf.

38. Adair LS, Popkin BM. Birth weight reduces the likelihood of breast-feeding among Filipino infants. J Nutr. 1996:126:103-12.

39. Agrasada GV, Ewald U, Kylberg E, Gustafsson J. Exclusive breastfeeding of low birth weight infants for the first six months; infant morbidity and maternal and infant anthropometry. Asia Pac J Clin Nutr. 2011:20:62-8.

40. Saha KK, Frongillo EA, Alam DS, Arifeen SE, Persson LA, Rasmussen KM. Use of the new WHO child growth standards to describe longitudinal growth of breastfed rural Bangladeshi infants and young children. Food Nutr Bull. 2009;30:137-44.

41. Launer LJ, Forman MR, Hundt GL, Sarov B, Chang D, Berendes HW, Naggan L. Maternal recall of infant feeding infants is accurate. J Epidemiol Community Health. 1992;46:203-6.

42. Tomeo CA, Rich-Edwards JW, Michels KB, Berkey CS, Hunter DJ, Frazier AL, et al. Reproducibility and validity of maternal recall of pregnancy-related events. Epidemiology. 1999;10:774-7.

43. Natland ST, Andersen LF, Nilsen TIL, Forsmo S, Jacobsen GW. Maternal recall of breastfeeding duration twenty years after delivery. BMC Med Res Methodol. 2012;12:179.

44. Saha KK, Billah M, Menon P, Arifeen SE, Mbuya NVN. Bangladesh National Nutrition Services: Assessment of Implementation Status. World Bank Studies. Washington, DC: World Bank; 2015. 